\title{
Nobel prize winner Christian de Duve. From insulin to lysosomes
}

Jean-Pierre Tricot

Catholic University of Leuven (Belgium)
"Neglect of the history of medicine sets in motion the dismal cycle of medical science which, turning almost without metabolism, repeatedly brings to light the same material."

Rudolf Virchow, the founder of cell pathology, (1851)

cose, Insulin and Diabetes", the subject that was to comprise the focal point of his interest during the first third of his career.

In 1946 he gained his degree of Master in Chemistry. Thereafter, he trained in biochemistry in the laboratory of Hugo Theorell at the Medical Nobel Institute in Stockholm, as well as at Washington University, with Earl Sutherland, under Carl and Gerty Cori. De Duve became lecturer at the University of Louvain in 1947 and full professor in 1951.

\section{After the fifties}

Until the beginning of the fifties his research work concentrated upon insulin and glucose, focusing, during the last two thirds of his scientific curriculum, on certain particular features of cellular biology. While studying the enzymatic aspect of carbohydrate metabolism, de Duve separated and analysed different cell components and discovered two new ones: the lysosomes in 1955 and shortly thereafter the peroxysomes. In 1960 he obtained the Francqui Prize, Belgium's most prestigious prize for science. In 1962 he was appointed professor at the Rockefeller Institute of New York.

In 1974 de Duve received the Nobel Prize in Physiology and Medicine, together with Albert Claude and George Palade, "for their discoveries concerning the structural and functional organization of the cell". During the same year he created a
Address correspondence and requests for reprints to: Jean-Pierre Tricot, Catholic University of Leuven, Belgium Received 09-11-05, Revised 20-01-06, Accepted 10-02-06 
new Institute, the International Institute of Cellular and Molecular Pathology (ICP) at the new site of the Louvain Medical School in Brussels. He became professor emeritus in Louvain in 1985 and in New York in 1988. Since then he has written a number of books on the origin and evolution of life. $\mathrm{He}$ plans to devote his remaining years to further probing what, if anything, our growing understanding of life and the mind can tell us about the structure of the universe and the meaning of life.

\section{II - THE ACTION OF INSULIN ${ }^{2,3}$}

As already mentioned, the research work of Christian de Duve initially focused on the working mechanism of insulin. At the age of 18 years, upon entering Prof. J. P. Bouckaert's laboratory of physiology, he elected to join the insulin group. Before 1921 different studies had been carried out by means of injection with pancreatic extracts in diabetic dogs (Minkowski in 1889, Zuelzer in 1906, Scott in 1910, Paulescu in 1916, Kleiner in 1919). In 1922 insulin was discovered by Best and Banting, Banting winning the Nobel Prize for this achievement in 1923, this in collaboration with MacLeod, the director of the laboratory in Toronto where Banting and Best were working.

\section{The peripheral effect of insulin}

At the time, several laboratories around the world (Dale, Best, Cori) were endeavouring to gain insight into the mechanism of action of insulin, with two schools of thought presenting opposing views: most scientists proposed a peripheral muscle effect; a minority were advocates of a glusoce over production by the liver.

\section{The compensation dose of glucose $e^{2}$}

Bouckaert stated that the injection of insulin could generate an increased amount of blood sugar only because hypoglycaemia provokes a discharge of epinephrine, which stimulates hepatic glycogenolysis. To avoid this artefact he gave a continuous intravenous infusion of glucose adjusted to keep the blood sugar unchanged: the amount of glucose injected to maintain a constant blood sugar level was equal to the extra amount of glucose used under the influence of the hormone, but only until a maximal level, whereat further increases in the amount of insulin injected no longer increased the compensation dose.

\section{The hepatic action of insulin ${ }^{3}$}

Subsequently, de Duve found that hepatectomized dogs needed considerably less glucose to be kept normoglycemic after injection of a supramaximal dose of insulin than did an intact animal $\mathrm{He}$ thus proved that the liver is the major site of insulin action.

\section{Publication of the first results (1944-1947)}

The first results were published in the renowned journal published by Nobel Prize laureate Corneille Heymans, "Archives Internationales de Pharmacodynamie et de Thérapie", where, between 1944 and 1946, a series of papers written by de Duve appeared. A prominent Parisian publisher, Masson, agreed in 1945 to publish a 400-page book entitled "Glucose, Insuline et Diabète". The experimental work therein described was the subject of his $\mathrm{PhD}$ dissertation in 1945.

\section{III - THE (RE-)DISCOVERY OF GLUCAGON ${ }^{4}$}

It was in May 1944 that de Duve suddenly remembered a substance largely forgotten since its discovery by Murlin and Kimbell in 1923, namely glucagon, a hyperglycemic impurity that accompanied insulin through several purification steps, but could be removed by crystallization.

De Duve proved that the American Lilly-insulin, used by Bridge, was contaminated by glucagon, whereas the insulin he used namely the Danish Novo-insulin, was not. As corroboration, he injected one rabbit with Lilly, another with Novo, demonstrating that, while the Lilly insulin provoked an initial hyperglycemia, the Novo type did not.

These results were included in the Physiological Reviews paper published in 1947, following which the Lilly-company modified its method of purification. Thus, the statement one can read in the latest edition of the Goodman and Gilman's "Pharmaceutical Basis of Therapeutics" that, subsequent to the discovery of glucagon, it was not recognized as an important hormone, is not entirely correct. 


\section{COMPLEMENTARY BIOCHEMICAL TRAINING}

During the Second World War, de Duve, having served a short time in the army, escaped from a prisoner's camp and returned to Louvain to complete his studies. He was convinced that the problem of insulin action needed to be approached by means of biochemical methods. He obtained his degree of Master in Chemistry in 1946 with a work dealing with the purification of the recently discovered penicillin. From 1946-47, he trained more specifically in biochemistry at the Medical Nobel Institute in Stockholm in the laboratory of Hugo Theorell (Nobel Prize for the nature and mode of action of oxidation enzymes) where he was able to achieve the crystallization of human myoglobin, and thereafter at Washington University under Carl and Gerty Cori (Nobel Prize 1947 for the discovery of phosphorolysis) in the laboratory of Earl Sutherland (Nobel Prize for his discoveries about the mechanism of action of hormones).

\section{Glucagon and the alpha-cells}

Sutherland's mode of research was pragmatic and intuitive, relying more on instinct and flair than on rational reasoning. Together with de Duve, he showed that glucagon was made not only by the pancreas but, surprisingly, by the gastric mucosa and certain other parts of the digestive tract. Using a variety of approaches, they obtained strong evidence indicating that pancreatic glucagon was most likely a hormone made in the endocrine islets by cells differing from the insulin-producing beta cells, presumably the alpha cells.

Sutherland called glucagon the hyperglycemicglycogenolytic (HG) factor. However, out of respect for the original discoverer, the American Murlin, de Duve decided to re-institute the old name, glucagon. It was a real (re)discovery of this hormone.

The alpha-cell hypothesis was confirmed as soon as de Duve came back to Belgium: treatment of guinea-pigs with cobalt that selectively damaged the islet alpha cells caused a drastic lowering of the glucagon content of the pancreas.

\section{IV - THE LYSOSOME STORY,5}

\section{The study of enzymes}

The Lilly company, far from penalizing de Duve for showing up their product to be impure, took over the purification and sequencing of glucagon. Moreover, they financially supported the professor to establish a successful laboratory in Louvain. From then on he specialised in subcellular biochemistry and cell biology. Among other subjects, he studied the distribution of enzymes in rat liver cells using rate-zonal centrifugation as well as by fractionation of the cells.

In 1955 de Duve tried to characterise the hexose phosphatase shown to account for the unique ability of the liver to form free glucose: a glucose-6-phosphatase, precipitated at acid $\mathrm{pH}$, and therefore interpreted by de Duve as being attached to some intracellular lipoprotein structure, the endoplasmatic reticulum membranes.

\section{The discovery of lysosomes}

However, the other enzyme, acid phosphatase, unspecific for the glucose metabolism, also revealed itself as particle-bound to another kind of elusive new particles: the digestive bodies of lysosomes and the peroxysomes. These particles were latent in fresh liver and only detectable after successive congelation and decongelation. From then on the research work of de Duve would be focused on these two particles and on inborn lysosomal storage diseases.

Working with Christian de Duve was Jacques Berthet, still a medical student at that time, but possessing an unusually mature and rigorous mind. $\mathrm{He}$ applied himself to setting up the technique with precision, paying equally meticulous attention to all physical parameters. One could, in fact, compare the contribution of undergraduate student Jacques Berthet to this work with the role played by undergraduate student Charles Best in the discovery of insulin by Banting.

\section{Professorship in New York}

In 1962 de Duve was appointed professor at the Rockefeller Institute of New York, now the Rocke- 
feller University, the very same institution where the Belgian scientist Albert Claude had made pioneering studies between 1929 and 1949, developing the technique of cell fractionation by differential centrifugation, and where the American researcher of Romanian origin, Georges Palade, expanded upon research into electron microscopy discovering and describing a large number of cell fractions.

\section{The Nobel Prize}

In 1974 de Duve, Claude and Palade shared the Nobel Prize in Physiology and Medicine "for their discoveries concerning the structural and functional organization of the cell". However, it can also be considered that the discovery of lysosomes was stimulated by the research work carried out into the carbohydrate metabolism.

Throughout his career de Duve has maintained contact with a number of Nobel Prize winners. For the publication of his first paper he relied upon Corneille Heymans and Henry Dale. He trained in biochemistry in the laboratories of Carl and Gerty Cori, Earl Sutherland and Hugo Theorell. At the Rockefeller University he worked with Albert Claude and George Palade with whom he shared the Nobel Prize.

\section{V - AFTER THE NOBEL PRIZE}

\section{The ICP}

In 1975 de Duve created the International Institute of Cellular and Molecular Pathology (ICP) located at the new site of the Louvain Medical School in Brussels. The aim of the ICP has been to accelerate the translation of basic knowledge in cellular and molecular biology into useful practical application. The ICP now employs 270 full-time research scientists and has also established a fruitful relationship with the famous Ludwig-Institute for Cancer Research.

\section{Hers and the glycogen metabolism ${ }^{5}$}

One of de Duve's co-workers, Henri Hers, remaining faithful to the carbohydrate metabolism, elucidated the pathway of fructose metabolism, and discovered fructose 2,6 biphosphate, important in the glycogen metabolism. Around 1965 Hers became interested in the glycogen storage diseases such as type II glycogenesis, or Pompe's disease, in which there is a deficient acid hydrolase enzyme belonging to the lysosomes. The concept of inborn lysosomal disease was born, a notion applicable to most polysaccharidoses, lipidoses and other storage diseases.

\section{The origin of life}

During the past few years de Duve has become increasingly interested in the origin and evolution of life and has written four books concerning this subject, acknowledging, nevertheless, that it remains a speculative field. His work has contributed to the emerging consensus that the endosymbiotic theory is correct; this idea proposes that mitochondrion, chloroplasts and possibly other organelles of eukaryotic cells originated as prokaryote endosymbionts, which came to live inside eukaryotic cells. This, however, is another story.

\section{de Duve and the History of Medicine $e^{6,7}$}

Although he has written an autobiography and recently a paper about his 'love affair' with insulin, ${ }^{6}$ de Duve is not an expert in the History of Medicine, remaining, nonetheless, deeply convinced of its huge importance and value.

As a young medical student working in the physiology laboratory of Joseph Bouckaert in Louvain, de Duve's very first assignment was in the library. It was Bouckaert's opinion that an investigator should always start by getting thoroughly acquainted with the literature of his subject. During the International Congress for the History of Medicine ${ }^{7}$ that I organised 15 years ago in Antwerp, de Duve stated that we are beginning to have a sufficiently detailed understanding of the basic processes of life to be able to perceive pathology problems in the light of entirely different times. He was personally convinced that the second half of the last century had seen the greatest revolution in knowledge in the entire history of mankind, all the more important because it concerns the very nature of life, including our own. In conjunction with a profound and comprehensive understanding of living processes, he told us, this revolution is also imparting to us powerful practical means of influencing and manipulating life, which 
were unheard of a mere 20 years ago. It is too early to judge what impact these events will have on the history of medicine. In his opinion, this impact cannot be but equally revolutionary. This is very definitely the case of the astounding progress made in the study of diabetes.

\section{REFERENCES}

1. de Duve C 1975 Autobiography, Les prix Nobel en 1974. In: Wilhelm Odelberg (ed) Stockholm.

2. Bouckaert J, de Duve C, 1947 The Action of Insulin. Physiology Rev 27: 39-71.

3. de Duve C, Pressman BC, Gianetto R, Wattiaux R, Appelmans F, 1955 Tissue fractionation studies. 6 In- tracellular distribution patterns of enzymes in rat-liver tissue. Biochem J 60: 604-617.

4. Sutherland EW, de Duve C, 1948 Origin and distribution of the hyperglycemic-glycogenolytic factor of the pancreas. J Biol Chem 175: 663-674.

5. Hers HG, 1965 Inborn lysosomal diseases. Gastroenterology 48: 625-633.

6. de Duve C, 2004 My love affair with insulin. J Biol Chem 279: 21679-21688.

7. de Duve C 1991 Some reflections on the History of Medicine. In: Proceedings of the XXXII ${ }^{\text {th }}$ International Congress on the History of Medicine, Antwerp, 3-7 Sept. 1990, Fierens E, Tricot JP, Appelboom TM, Thiery M (eds) Societas Belgica Historiae Medicinae, Bruxelles; pp, 31-35. 